\title{
Calle14: un "media" de distribución social de conocimientos
}

\section{Pedro Pablo Gómez}

Universidad Distrital Francisco José de Caldas ppgomezm@udistrital.edu.co

Cómo citar este artículo: Gómez, Pedro Pablo (2018). Calle14: un "media" de distribución social de conocimientos. Calle 14: revista de investigación en el campo del arte 13(24). pp. 250-252. DOI: https://doi. org/10.14483/21450706.13493 
Hace varios años el teórico español José Luis Brea (La era postmedia: Acción comunicativa, prácticas (post)artísticas y dispositivos neomediales) se ocupó de aclarar la confusión existente entre los conceptos de multimedia y multisoporte. Esto debido a que suele llamarse multimedia a lo que simplemente es multisoporte. Se dice que una instalación es multimedia porque podría incluir fotografías, pinturas, videos, objetos, sonido, entre otros. Un lienzo es un soporte y también es un soporte el papel en el que se imprime una revista. Pero una revista es un "media" así esté hecha sobre papel, un soporte electrónico o en cualquier otro soporte. La revista es un "media" porque está concebida como un medio de distribución social de conocimientos. Y en esto consiste su importancia y su valor. Por tal razón, las revistas no pertenecen propiamente a las instituciones que las editan, ni a los editores, ni a los comités editoriales y ni siquiera a los autores; pertenecen a las comunidades académicas y no académicas que, en sentido amplio, se apropian de las revistas como un medio efectivo para su propia constitución como comunidades de sentido.

De lo anterior somos conscientes en Calle14 desde hace más de una década. Y estamos convencidos de que tenemos suficiente con el papel de mediadores, entendido como tarea ética y política para la distribución de conocimientos que sus creadores nos confían para que circulen en las páginas de la revista.

Este número abre con el artículo El genio secreto del catalejo (Kikkertens Hemmelighedsfulde Aand) de la artista Sandra Rengifo con el que Fernando Escobar entra en diálogo creativo desde su particular perspectiva de análisis. Continúa con El Jardín perdido, de Hanna Ramone, donde la artista construye una reflexión acerca del problema social de los feminicidios, fenómeno que afecta a mujeres de todas las edades y nacionalidades, quedando casi siempre impune. Jacques Rancière, nuestro autor invitado, se ocupa de repensar la modernidad estética para mostrar cómo se puede llegar a una política inspirada en el regimen estético. Esta política de indeterminación y de libertad da origen a la idea de una política propiamente estética, de un comunismo estético en el que hay comunicación directa entre las formas del arte y de la vida. A su vez, Sofía Villena indaga por la relación de los espacios físicos y psicológicos en la vivencia de una multiplicidad de masculinidades en el arte costarricense. Enseguida, Marcela Quiroga Garza afirma que exite una relación entre las ideas del artista de Joseph Beuys y ciertas prácticas artísticas contemporáneas, especialmente las que tienen que ver con acciones directas, activismo y proyectos de desarrollo cultural. Más adelante, Jesús Antonio Villalobos Rubiano se ocupa de una faceta poco explorada por los estudiosos de Francisco José de Caldas: sus aportes al análisis, práctica y enseñanza de la arquitectura en la Nueva Granada. Por su parte, Adriana 
Roque Romero aborda la pregunta sobre el lugar del arte en la coyuntura de la transición al posconflicto colombiano, en relación con las políticas culturales y la potencialidad de la actividad artística como práctica disensual. En su artículo, Iván Gómez Beltrán, analiza una obra de Marina Abramović con el fin de evidenciar la idea de la artista acerca del arte como agente de transformación social. Cynthia Ortega Salgado y Juan Mojica Arias, proponen los conceptos de deseo, ritmo y desaparición como estrategias para acercarse al espinoso tema de la relación arte y lenguaje. Jesús Antonio Pardo León, por su parte, desde un análisis de caso, nos propone una contextualizacion del fenómeno narco en Colombia. Con una visión ecosistémica, Elizabeth Garavito López da cuenta de la construcción colaborativa de microuniversos (pequeños relatos que se construyen con plantas y objetos dentro de una maceta). Luego, Adrià Harillo Pla, realiza una crítica a algunas obras de arte y propuestas expositivas presentes en galerías de arte contemporáneo ubicadas en M50, distrito del arte de la ciudad de Shanghái. A su turno, Albeiro Arias, partiendo del análisis de una obra del artista Nadín Ospina, reflexiona acerca del uso de los medios de comunicación como articuladores ideológicos y acerca de la obra de arte como medio de resistencia al poder. Finalmente, Matías David López, a partir del concepto de "escena artística", indaga las características de los proyectos culturales de la ciudad de La Plata, Argentina, sus modos de gestión, formas de articulación y políticas estéticas.

Bienvenidos a este nuevo recorrido semestral, tan necesario para seguir tejiendo vínculos y comunidades estéticas y políticas desde el campo de las artes.

\section{Referencia}

Brea, J., Luis. (2002). La era postmedia: Acción comunicativa, prácticas (post) artísticas y dispositivos neomediales. Barcelona: Consorcio Salamanca. 